\title{
Confronting Occupation with Cultural Stability in Lameece and Jacob's Food and Fadwa
}

\author{
Sahar Mokbel (PhD) \\ Lebanese University, Lebanon
}

Doi: 10.19044/esj.2018.v14n5p328 URL:http://dx.doi.org/10.19044/esj.2018.v14n5p328

\begin{abstract}
The following paper demonstrates the life in Palestine and the daily conflicts that take place due to Israeli occupation of the land. Its purpose is to shed the light on the significance of confronting occupation with cultural stability. Through the play Food and Fadwa, we are introduced to a Palestinian family suffering from the ache of occupation. However, Fadwa's Palestinian cuisines act as means of resistance against the Israeli attempts of cleansing the Palestinian culture and heritage.
\end{abstract}

Keywords: Occupation, resistance, stability, Palestinian identity

\section{Introduction}

Lameece and Jacob's Food and Fadwa is a contemporary play that takes the reader into the heart of Palestine where every single delightful Palestinian memory is turned bitter by the cruel and harsh Israeli occupants. The paper in hand has two main purposes. First, it is meant to show how cultural stability can stand as a means to confront the harsh occupation. Second, it is a cry against all forms of oppression taking place against the innocent Palestinian citizens. By applying the cultural and historical approaches, this study proves that cultural resistance is a necessity that serves in preserving the Palestinian culture from degeneration.

I.

As long as Palestine is occupied by Israel, the Palestinians are trapped between two pitiful choices. Either they leave their homeland, or they bear the daily exploitation, horror, and terror practiced by the Israeli government on civilians in Palestine. Being stripped out of their land, their rights, and all means of survival, what remains is a culture, a bundle of memories, and a dignity to protect and to save from the hands of the occupation which tries to wipe out every aspect that is linked with the Palestinian identity and heritage. 
Edward Said pictures what is going on in Palestine and presents the goal of the Israeli government saying that its plan is "to starve, beat down, and bring the Palestinians to their knees" (Barsamian. Said, 135, 2003); Said adds that such a plan would never succeed as long as "Palestinians are staying on their land. They are not leaving. There is desperation and unhappiness but all the signs, as in all colonial wars, point to an upsurge of resilience and a will to resist." (Barsamian. Said, 135, 2003) If this is the aim of the Israeli government, then they have to face stubborn Palestinian citizens who are ready to sacrifice everything left for the sake of protecting their culture and identity from diaspora.

The Palestinian civilians living in their homeland have to fight in order to survive; they ought to challenge the atmosphere of desperation created by the Israelis by every means of survival. Their struggle is that of a nation that longs for peace and freedom despite all the terror and cruelty that take place repeatedly. Out of this comes the importance of preserving the Palestinian culture; it is an act of sticking to one's heritage regardless of the cost that has to be paid.

When speaking about the Palestinian -Israeli conflict, we find that scholars have almost ignored questions on popular culture or at least marginalized this aspect due to the severe and violent acts of the Israeli occupation (Stein. R, 2005), yet in Lameece and Jacob's Food and Fadwa, the authors present aspects of the Palestinian popular culture as means of defense and rigidity against the Israelis.

Lameece and Jacob's Food and Fadwa is a contemporary play that has been produced in 2011and has received the Edgerton Foundation New American Play Award in 2012. The play is about a Palestinian family celebrating a marriage occasion in Palestine despite the hazardous fights taking place; it is, in fact, a cry not only against the Israeli occupation, but also against cleansing the Palestinian culture from its traditions and norms of everyday life. It is a window that sheds the light on the forgotten Palestinian popular culture with details on the Palestinian daily life and popular culture that needs to be preserved and highlighted due to its role in confronting the occupation.

The play takes place at the Farranesh family home which is located in Bethlehem, West Bank of Palestine. Bethlehem is only ten kilometers away from Jerusalem, the Holy City and the capital of Palestine, where daily conflicts take place between the Palestinians and the occupants. Bethlehm, too, is a holy and a sacred place that carries many values; this is justified by the role given to it according to Christianity since Jesus Christ was born there. The setting of the play is, thus, significant, for it is related to the history of Palestine; the 'Holy Land' as regarded by the great monotheistic religions (Swanson, 2000). 
Fadwa, the protagonist of the play, starts by addressing the audience: "Hello and welcome to another episode of Food and Fadwa. I am your host Fawa Faranesh!" (Najjar, 142, 2007) With her simple dress and bandana, Fadwa, from her little kitchen, prepares the audience to a play that is rich with episodes from the Palestinian heritage and culture. Busy with her younger sister's upcoming wedding, Fadwa tells that her visitors are "coming all the way from New York!" The audience, then, is to expect two groups of Palestinians; the first are those who continue to live in Palestine despite the harsh occupation and are represented by Fadwa and her father; on the contrary are those who have immigrated to the United States yet come to Palestine on occasions and are presented as the 'New Yorkers'. Two of these New Yorkers are Youssif, Fadwa's former lover, and his bother Emir. The wedding that is supposed to take place is that of Emir and Dalal, Fadwa's younger sister. Yet, before the marriage would take place many incidents take place to show the brutality of the Israelis and the importance of stability and sacrifice in preserving one's nation.

Fadwa's kitchen is not any kitchen; it is symbolic for it is rich with all Palestinian traditional food. The food cooked by Fadwa in her kitchen takes the audience to Palestine, and to the forgotten Palestinian popular culture. Each type of dish has a story and is a heritage by itself. One of the aims of the authors, therefore, is to shed light on such a heritage in order to preserve it from loss. "Our first dish, my favorite. Baba Ghanoush. ...Do you know what it means Baba Ghanoush? 'Spoiled old daddy.' Because the creator of this dish would mash up eggplant to feed her to her father, who was old and toothless and could not chew" says Fadwa. (Najjar, 143) Fadwa's food can also be linked to her own story, for she lives with her old aged father whom she takes care of and cooks food for.

To this favorite plate, Fadwa adds an essential ingredient: "It is only the most important ingredient in an Arab kitchen. Zeit Zaytoun. Oil of olives. Extra virgin. Like me." (Najjar, 143) Olive oil is as pure as a virgin, just like Fadwa herself; it might be because both are rigid and strong enough to face the occupants and the changes they want to bring to Palestine. The olive oil is well known not only as a food ingredient but also as a symbol of rigidity since the olive tree can stand against all forms of catastrophes and storms; it can also live hundreds of years (Helstosky, 2009). The storm, then, becomes the occupation with its manipulation of the land and the citizens while Fadwa stands as rigid as an olive tree facing such manipulation by preserving the heritage of her culture.

Apart from the food, yet still in Fadwa's kitchen, Emir and Dalal appear talking about one of the issues that is to be highlighted; it's the Israeli checkpoints: 
Emir: This isn't even everything! We had to leave most of it at the check point.

Fadwa: Checkpoint? In the neighborhood?

Dalal: Yes, the mobile one near the school. The army set it up last week.

Emir: Ifeel more secure.

Dalal: They were searching everyone. Taking things. Like during the incursions.

Emir: Even the box of pastries! I should have eaten it all.

Dalal: I got the cutest gift, a necklace with a garnet. The soldier took it and put it on his soldier girlfriend! Right in front of me! (Najjar, 143)

Emir, returning from America to his native land, has to pass by the checkpoints which the Israeli government has created for the sake of Israel's security. Yet the authors present the hypocrisy of such an issue, for the checkpoints are rather used to mistreat and to trouble the Palestinian citizens. When passing through a checkpoint, a Palestinian is 'subjectified'; that is, he becomes a subject of Israeli power (Ryan, 2015). Every Palestinian is to be searched and abused at these checkpoints; Dalal, for instance, is stolen by an Israeli soldier who rudely takes her necklace to place it on his girlfriend's neck. The Israelis, then, give themselves the right to usurp all the Palestinian goods while their 'security' turns to be the means they use to legalize their barbarous actions.

The second visitor coming from New York to Palestine is Youssif. Fadwa, Emir, and Dalal are worried since any Palestinian visiting Palestine will definitely be stuck at the borders. Fadwa wonders: "I hope they don't hold him too long at the border", yet Emir sarcastically replies: "Eh, it's nothing. Another 7, 8 hours. Maybe 30. Big deal? (Najjar, 145) It seems that it is intended to make the Palestinians suffer from humiliation. This isn't a new issue; since the dawn of history, wherever occupation has existed, humiliation and torment have been the tools by which the civilians have been forced to subdue and surrender. Is it meant, hence, for the Palestinians to accept their current situation? Resistance is surely the only means through which they can confront the Israeli power and oppression, for 'where there is power, there is resistance' (Medina, 13, 2013). Consequently, resistance is needed to regain the Palestinian dignity and land.

Hayat, too, is another visitor coming from America to attend the wedding. Unaware of the nature of life in the occupied Palestine, she questions the reason behind the presence the 'wall' all over the country:

Hayat: That wall is-I have no words. I mean, I always knew-but seeing it. It's shocking.

Youssef: It's our national landmark!

Emir: Yep. Our Great Wall of Palestine! 
Hayat: It's practically in your backyard.

Dalal: It's in everyone's backyard.

According to official Israeli documents, the wall is a 'security barrier', yet to the Palestinians, it is an 'annexation wall' and an 'apartheid wall' (Backmann, 3, 2006). Through it, not only the Israeli government has practiced discrimination against the Palestinian civilians, but also more Palestinian land has been usurped. This wall that is built to separate the different regions of Palestine is just like the knife that is placed at the center of the heart. Dividing Palestine into bits and pieces is one of the methods that can turn the nation into a weak and a fragmented one. This wall says Hayat is in 'everyone's backyard'; every Palestinian can witness the wall and live the tension of being separated from his family members, neighbors, and beloved ones. The wall, then, acts as evidence to the cruelty of the Israeli authorities that try to weaken and to imprison the Palestinian civilians by every possible method.

Apart from the issue of the wall comes that of the permits; unless the Palestinians have a permit from the Israeli government, they won't be allowed to pass from one area to another. Yet, even with the presence of a permit, the passage seems to be complicated:

Hayat: Why do you need a permit? Jerusalem is like, 15 miles away? Youssef: Five.

Hayat: Five miles?

Dalal: It used to take 10-15 minutes to get there. Now, more like 5 hours, with the checkpoints and roadblocks. But that's only if you are lucky enough to have the permit. (Najjar, 155)

The hardship of the Palestinians is endless; from Bethlehem to Jerusalem would take more than five hours instead of five minutes. The Israelis have added roadblocks and checkpoints that act as hindrances; it is significant, then, to shed light on the daily miseries the Palestinians go through. Consequently, their right to live a normal life is usurped and replaced by gross injustice.

Following occupation, Palestine has been divided into areas, and of these areas Emir makes an analogy with the food placed on the kitchen table to clarify the idea for their American visitor Hayat. The family, thus, while gathering to eat their lunch divide the table as if it were a map for Palestine and each type of food placed on it becomes symbolic.

Emir: Enough! Let me explain to our American visitor here. Move your plates. Fadwa, Dalal hold these. (He hands them the hummus and the salad.)

Dalal: What are you doing?

Emir: Okay. This table here is all of the West Bank. Let us say this hummus represents Area A-Let's just put few dollops here and there. 
Fadwa: Yee, what are you-

Emir: And now these piles of rice are Area B-

Youssif: And these little pieces of napkin are Area $C$ -

Fadwa: Ya Allah, you're making a mess!

Emir: Visual aids are very important. Now, Area A-the hummus-are areas run by the Palestinian Authority. Supposedly. Authority on what-God knows. The piles of rice, Area B, are areas that are Palestinian run but with Israeli security. Area $C$, the pieces of napkin, are areas that are Israeli controlled. And all these little pieces of chicken are undetermined areas.

Youssif: And all these bits of salads are the Israeli settlements-

Emir: And all of this salt-those are checkpoints. Hundreds of them sprinkled all over the place. (Najjar, 155)

It's clear, then, from this analogy that Palestine is divided into three main areas. To begin with, Area $\mathrm{A}$ is the hummus area, this type of food 'hummus' is symbolic for it is considered to be one of the traditional food; hence it stands for the Palestinian stability. This area is actually run by the Palestinian authority, yet Emir sarcastically says 'authority on what'. This obviously shows that there is no true Palestinian authority, for the Israelis are capable of controlling all the areas even the one that is under the Palestinian authority; for instance, the Palestinian civilians are to be arrested and their houses are to be searched every now and then; "interruptions, curfews, detentions of neighbors and colleagues, sit-ins and merchant's boycotts" comprise the daily schedule of the Palestinian citizens (Lockman, 30, 1989). Therefore, the Palestinian authority turns to be a frail one that lacks the power of providing peace and security for the citizens living in this narrow area. Moving to the second area, Area B is represented by the 'rice'; it is Palestinian run, yet with Israeli security. Rice usually symbolizes peace and security; however, the reader, here, shall stand at the issue of 'security'. Definitely, it is a fake security that Israel uses as a tool to exploit this area and to spread horror among the civilians. The third Area turns to be that which is totally occupied by the Israelis; it's represented by the napkins rather than food. The food in the play stands for the culture. Israel has no culture; therefore, it cannot be represented by any type of food. Napkins are the best representative, they're a means of cleansing the dirt, and Israel needs to be cleared from the occupied land of Palestine.

In addition to the three main areas mentioned by Youssef, there are other undetermined areas which are represented by the 'little pieces of chicken'. When chicken is present at meals, each tries to take a piece of it; consequently, these undetermined parts of Palestine are similar to the pieces of chicken. While Palestinians try to preserve these areas, the Israelis in return have ambitions of usurping them. 
To clarify how life goes on in Palestine, Youssef and Emir add the cups, the bits of salad, and the salt to represent respectively the wall, the Israeli settlements and the checkpoints. The wall is the border between one area and the other; the bits of salad stand for the Israeli settlements for the Israeli people are a mixture of different nationalities (salad); and the salt 'those are checkpoints. Hundreds of them are sprinkled all over the place'. The salt, when spread over the land deprives agriculture and thus stops life. The checkpoints, too, are similar to the salt in a way that they stop the life from going on normally in Palestine.

Emir does not stop here; he, the, uses the 'fork' and the 'bread' to make more sense of his discussion:

Emir: This fork will be the permit.

Youssif: Genius brother.

Emir: Now Bethlehem is here in Area A, in the hummus. If you want to get from hummus to hummus, you don't need a fork. You can just use bread.

Hayat: What does the bread represent?

Emir: Nothing. It's just the best way to eat hummus.

The fork is a means for eating food in the modern way, yet this method of eating isn't the traditional method in Palestine; it is just brought from the West. On the contrary, there is the bread which is the traditional and the original method of eating food. In the play, the fork stands for the permit which is necessary to have when going through the undetermined areas of Palestine. These permits have never existed before occupation and people used to pass from one place to another freely. The forks, then, act as the barriers while the bread turns to represent free acts, life and habits. Consequently, life is much better without forks, barriers; in Palestine, people have lived freely before the Israeli occupation, yet following the occupation, their life was ruined and their freedom was usurped.

Through Emir's voice the authors turn to present the truth about Oslo Accords which were announced in 1993. The accords stood as an agreement between the Israeli government and the PLO team (in the Jordanian Palestinian delegation to the Middle East Peace Conference). Based on those accords, the Israelis and the Palestinians "strive to live in peaceful coexistence and mutual dignity and security and achieve a just, lasting and comprehensive peace settlement and historic reconciliation through the agreed political process." (Oslo Accords, 1993) However, the miserable life of the Palestinians show that all agreements with the Israeli authorities are fake ones since the Israelis give themselves the right of violating such agreements, claiming that their actions are necessary for their own security: 
Emir: It's Oslo! So, if you want to go from hummus to rice, you still don't need a fork. And, Area C, what's Israeli controlled, doesn't need bread or a fork because no one wants to eat napkin.

Youssif: Exactly.

Hayat: It's making sense! So where is Jerusalem in relation to all this?

Emir: Jerusalem is here, in the undetermined space, the chicken.

Hayat: Which you need a fork for!

Emir: Aywah! Exactly!

Hayat: And no matter what, you always have to go through the saltthe checkpoints!

Emir: That's right. Smart girl! See before, we didn't need forks. We just ate chicken by our hands. But they said, "you people are bunch of animals! How can you eat chicken with your hands? You must use forks!" (Najjar, 156)

Jerusalem, the capital of Palestine, is considered to be one of the undetermined areas, yet the Israelis have the rapacity to overrun it. Emir, therefore, is to mock all the fake agreements with Israel, for such agreements support the Israelis who give themselves the right to exploit the Palestinian lands whenever it's possible. The Palestinians are viewed as 'bunch of animals' because they use their hands for eating rather than forks. Emir's message is that it's much better to use hands, to live simply, and to be traditional rather than to accept the fake modernity which is a mask used to claim security while in fact it tries to hide the ugly truth of the daily imposition taking place in Palestine.

Fadwa's table, the food, and the kitchen are an image of Palestinian traditions. Fadwa, busy with preparing food for her visitors, tells the audience a story about each type of food. Their next breakfast will be 'mana'eesh'. This traditional Palestinian food is well known to be eaten on breakfasts, for it is like "a warm bath and a fire place and a hug all rolled into one savory, delicious bite", says Fadwa (Najjar, 158). The mana'eesh is food for the soul, it's the cure for the ones who need love, and who need a nation's embrace. When eating mana'eesh, her visitors not only will taste the delicious oil and Zaatar spread on it, but also will feel at home after being away from their motherland Palestine.

Following the breakfast, Fadwa is packing up other sorts of food for her sister's wedding. She starts with the candied almonds; when describing it, Fadwa mentions that "it's the sentiment. Hard bitterness shelled in sweetness. Like marriage" (Najjar, 161). The candied almonds is a tradition that will never die, it holds both sweetness and bitterness, like marriage and maybe like the life in Palestine. If such traditions die, the nation too will die; therefore, preserving these types of food means preserving the Palestinian culture that has been inherited from one generation to another. With the presence of 
occupation, it's necessary to have people like Fadwa, stuck to their country's traditions and never accept losing it.

Fadwa's next dish is the 'tabbouli', a popular Palestinian salad that is served on almost all happy occasions. This dish, too, has its own story and its own symbols. First, this dish 'needs patience' since one has to chop the parsley finely and slowly. Moreover, the parsley by itself is symbolic for it "can grow in the bitter cold and then sprouts in the early spring, when everything else is still asleep. Because of this, it is thought to be a symbol of new beginnings. It is authentic and true to the culture from which it comes." (Najjar, 162) The message of Fadwa, then, is that a new beginning is always possible; all it needs is patience and the will to change. Palestine too deserves a new beginning; definitely, the spring of Palestine will come one day. One of the means for confronting occupation is cultural stability; hence, through her traditional food, Fadwa is trying to preserve her Palestinian identity.

One of the most loveable types of traditional Arabic plates is the 'mloukiyi' on which Fadwa says:"Mloukiyi was once thought to be a sexual stimulant and was banned by an Egyptian ruler in the $10^{\text {th }}$ century for its passion inducing effects! This little, leafy vegetable? Better be careful to whom you serve it." (Najjar, 164) This dish, too, has its history; it's known for its passion. Fadwa wants to serve this dish for her loved ones, and even without calling anyone, she finds Youssef rushing into her kitchen following the smell of her food: "Oh, mloukiyi. My favorite." This relationship between the Palestinians and their traditional food shows their attachment to their native land. Despite the fact that Youssef has been away from Palestine for a long period of time, his Palestnian identity, and his love to his country and to its traditions can never be surpassed or replaced. He, then, moves to grab fresh mint:

Youssif: I love the smell.

Fadwa: Shoo, you don't have mint in New York?

Youssif: Not like this. From the garden?

Fadwa: What's left of it.

(Youssif picks up a bottle of olive oil.)

Youssif: "Zeit Zaytoon't Zein"

Fadwa: We have about a dozen bottles left.

Youssif: You should preserve them. (Najjar, 163)

The conversation that appears to be about food is in reality about belonging. Youssif suffers from diaspora; though living in New York, he belongs to another nation, Palestine. To him, the mint of Palestine has a different smell from that of New York, and the olive oil is to be preserved. Youssif wants to regain what is lost; the food in Fadwa's kitchen symbolizes the culture that needs to be preserved. Consequently, preserving one's culture 
helps in creating a fixed identity and diminishes the aches of diaspora and occupation.

The wedding date was approaching, and Fadwa had almost prepared all the food needed for this occasion; however, all the preparations had to stop when the Israelis announced an immediate curfew. The announcement was as follows: "Mamnou'a al-tajawool! There is an immediate curfew effective immediately. Clear the streets! You are under a 24-hour curfew until further notice. Anyone left on the street will be arrested" Najjar (165). Bethlehem, where the Faranesh family live, belongs to Area A, which is supposed to be run by the Palestinian authority. On the contrary, it's evident that there are no limits for the Israelis who control all the areas and turn the life of the Palestinians into that of fear and horror. The days pass and curfew continues. No one is allowed to leave his home for a single minute, and the Faranesh family has to accommodate with such a terrible situation:

Fadwa: It's the fifth day of our special curfew series. The topic today: Rationing!... How to cook when facing starvation due to military incursion: A three-step guide. One: storing and canning food for future use. Two: finding creative ways to serve less food with the magic that is food presentation! And three: rationing. (Najjar,166)

Fadwa turns to be the food manager; unless she manages properly, the family has to face starvation. Such curfews are meant to make the Palestinians suffer and struggle to survive. Fadwa, sarcastically, continues to describe their miserable situation; it's ironic that though they live in Bethlehem, people go hungry. The term Beit LaHem means 'House of Meat' in Arabic, and 'House of Bread' in Aramaic and Hebrew (Najjar, 166). Consequently, their village is the house of meat and bread; how, then, food is absent? The food here stands for life; conversely, its absence refers to lifelessness. Life without justice, as that in Palestine is meaningless. It is ridiculous how the Israelis give themselves the right of violating others' rights; they practice terror and exploitation without being criticized or stopped. Even the media try to hide the aggressive actions practiced by the Israelis against the Palestinians and claim that such actions are held for the sake of the Israeli security. Such exploitation and terror are almost practiced daily in Palestine. This play is meant to shed the light on what is taking place in Palestine; consequently, the true image of the Israelis and the anguish of the Palestinians should be revealed.

The tenth day of the curfew approaches and the family begins to starve. All the wedding food has been eaten; nothing has remained but olive oil to keep them alive. The Israelis, too, have turned off the water, yet all this happens without any earlier warning. Fadwa, with her empty kitchen, has to end her food episodes: "No Food and Fadwa! Fasting is a sacred practice" (Najjar, 181) Fadwa is a food artist, so without her food, she faints and loses 
her means of resistance. With her traditional Palestinian food recipes, Fadwa was able to preserve her culture from decadence; therefore, her kitchen turns to be symbolic for it resembles a set of traditions, and an inheritance that must survive.

Youssif, then, starts pouring olive oil in the cups to offer it as a cure in this miserable state. On viewing the oil, Fadwa's memory of her father's words on olive trees emerges:

Baba: To appreciate God's great bounty, simply look, Fadwa, at the blessed olive tree. Its very branches a symbol for peace, its fruit a holy gift... The tree has a heart. That tube serves as its heart. What is the heart but the center of man's compassion and capacity for love? A tree loves. It has compassion for man. It gives us its breath so that we may live; teaches us to be rooted and steadfast and gives shelter to all who seek it.... (Najjar 182)

The olive tree and the father have an incomparable relationship, it is that compassion and love. The father gives the tree his care and love, and in return, it gives him its olive which has become the family's only means for survival; this oil is symbolic for it comes from God's blessed olive tree. Its branches symbolize peace, yet Palestine lacks peace. The olive tree is to the Palestinian land as the heart is to human beings. Without each, life cannot exist. Moreover, the olive trees stand for steadfastness and for the nation's identity that shall never be threatened by occupation. The message, here, for the Palestinians is to stand and to confront the Israelis who want to uproot them from their native land. Therefore, resistance becomes the only means for preserving their identity and achieving liberty and peace.

The curfew ends, but not before spoiling the family's dreams. The wedding is turned into a funeral; the father, being attached to his olive trees, went outside on the last day of the curfew to save his trees from being uprooted by the Israelis. These trees, being a part of the Palestinian identity and heritage, need to be preserved, and to Fadwa's father, the trees are his life. Fadwa's father is found dead beside his trees. Though he dies, his compassion for the land and its trees continues to survive in the heart of his daughter Fadwa. Following his death, all the members decide to leave Palestine except her. Youssef tries to convince her to leave, yet she rejects: "What's holding you here, Fadwa? You're free to go anywhere now", yet she responds with full strength and determination saying: "This is home. And someone has to find a home for these little trees." (Najjar, 185) Fadwa stands for steadfastness, and resistance; she, as her father, is one of the rebellious Palestinians who are ready to risk their lives for the sake of preserving their national identity. Definitely, she stays in Palestine and refuses to surrender to all the Israeli failed attempts of threatening the Palestinian civilians. She stands as stubborn as an olive tree, ambitious enough to continue her dignified life in Palestine as taught by her 
father: "My father used to say that for a new tree to grow, it must be planted in a clean fertile field, free from rotting roots, trunks or weeds" (Najjar, 185). She will take care of the olive trees, and at the same time her kitchen with the traditional Palestinian food she cooks will be her weapon to preserve her culture from deterioration: "Remember, no matter what you eat, the most important food of all is eklit'il hob. The food of love (Najjar, 185). She will cook the 'food of love' that is the traditional Palestinian food, for it gives Fadwa the strength to move forward and to protect her land. The play ends with Fadwa planting a new olive tree; this tree is the hope of a new future for Palestine; it is the future of a free and rigid country same as that of the rigid olive tree.

\section{Conclusion}

Food and Fadwa is definitely a play which highlights the significance of stability and steadfastness when confronting occupation. In addition to the play's special emphasis on preserving the Palestinian culture, it has also depicted the daily sufferings of Palestinian citizens. Fadwa's kitchen serves as a means against the Israeli failed trials of stripping the Palestinians from all their rights, including their cultural heritage. Consequently, preserving the Palestinian culture and the Palestinian food traditions is a cry against occupation and its attempts of shattering the Palestinians and changing their national identity. The Palestinian resistance, then, starts with resisting any form of compelled change and confronting it with stability.

\section{References:}

1. Barsamian, David. Said, Edward. (2003). Culture and Resistance, Conversations with Edward Said. Cambridge. South End Press.

2. Backmann, Rene. (2006). A Wall in Palestine. New York. Picador.

3. Estine,Stein, Rebecca. Swedenburg, Ted.(2005). Palestine, Israel, and the Politics of popular culture. Durham \& London. Duke University Press,

4. Helstosky, Carol. (2009). Food Culture in the Mediterranean. London. Greenwood Press.

5. Lockman, Zachary. Beinin, Joel. (1989). Intifada: The Palestinian Uprising Against Israeli Occupation. Washington. South End Press.

6. Medina, Jose. (2013) The Epistemology of Resistance. New York. Oxford University Press.

7. Najjar, Michael, (2014). Four Arab American Plays, Lameece Issaq and Jacob Kader's Food and Fadwa. United States. McFarland and Company.

8. Oslo Accords. (1993). Declaration of Principles. http://cis.uchicago.edu/oldsite/sites/cis.uchicago.edu/files/resources/C 
IS-090213-israelpalestine 38-

1993DeclarationofPrinciples_OsloAccords.pdf

9. Ryan, Caitlin, (2015) Bodies, Power, and Resistance in the Middle East: Experiences of Subjectification in the Occupied Palestinian Territories. Basingstoke. Routledge.

10. Swanson, R.N. (2000). The Holy Land, Holy Lands, and Christian History (Studies in Church History). United Kingdom. Boydell Press. 